\title{
A new Laplace transformation method for dynamic testing of solar collectors
}

\author{
Kong, Weiqiang; Perers, Bengt; Fan, Jianhua; Furbo, Simon; Bava, Federico
}

Published in:

Renewable Energy

Link to article, DOI:

10.1016/j.renene.2014.10.026

Publication date:

2015

Document Version

Peer reviewed version

Link back to DTU Orbit

Citation (APA):

Kong, W., Perers, B., Fan, J., Furbo, S., \& Bava, F. (2015). A new Laplace transformation method for dynamic testing of solar collectors. Renewable Energy, 75, 448-458. https://doi.org/10.1016/j.renene.2014.10.026

\section{General rights}

Copyright and moral rights for the publications made accessible in the public portal are retained by the authors and/or other copyright owners and it is a condition of accessing publications that users recognise and abide by the legal requirements associated with these rights.

- Users may download and print one copy of any publication from the public portal for the purpose of private study or research.

- You may not further distribute the material or use it for any profit-making activity or commercial gain

- You may freely distribute the URL identifying the publication in the public portal

If you believe that this document breaches copyright please contact us providing details, and we will remove access to the work immediately and investigate your claim. 


\section{A new Laplace transformation method for dynamic testing of solar collectors}

Weiqiang Kong ${ }^{\mathrm{a},{ }^{*}}$, Bengt Perers ${ }^{\mathrm{a}}$, Jianhua Fan ${ }^{\mathrm{a}}$, Simon Furbo ${ }^{\mathrm{a}}$, Federico Bava ${ }^{\mathrm{a}}$

${ }^{a}$ Department of Civil Engineering, Technical University of Denmark, Brovej, DK-2880 Kgs. Lyngby,

Denmark

*Corresponding author: Weiqiang Kong

Telephone:+4545251919Ｆax:+4545931755 Email:weiko@byg.dtu.dk

\section{Abstract}

A new dynamic method for solar collector testing is developed. It is characterized by using the Laplace transformation technique to solve the differential governing equation. The new method was inspired by the so called New Dynamic Method (NDM) [1] but totally different. By integration of the Laplace transformation technique with the Quasi Dynamic Test (QDT) model [2], the Laplace - QDT (L-QDT) model is derived. Two experimental methods are then introduced. One is the shielding method which needs to shield and un-shield solar collector continuously during test period. The other is the natural test method which doesn’t need any intervention.

The new L-QDT model with the shielding method are tested by TRNSYS [3] simulation. Experiments were carried out at Technical University of Denmark by using the L-QDT method and the natural experimental method. The identified collector parameters are then compared and analyzed with those obtained by the steady state test method and the QDT test method. The results comparison shows that the L-QDT method and the natural experimental method are also valid.

It can be concluded that the new Laplace test method can obtain reasonable and accurate collector parameters under transient weather condition.

Key words: solar collector, Laplace transformation technique, dynamic test method, solar collector parameters.

\section{Nomenclature}
$A_{P} \quad$ Aperture area of solar collector $\left(\mathrm{m}^{2}\right)$
c Specific heat capacity $(\mathrm{J} /(\mathrm{kg} \cdot \mathrm{K}))$
$F^{\prime} \quad$ Collector efficiency factor (-)
$F^{\prime} U_{L} \quad$ Heat loss coefficient at $T_{f}-T_{a}=0 \quad\left(\mathrm{~W} /\left(\mathrm{m}^{2} \cdot \mathrm{K}\right)\right)$ 


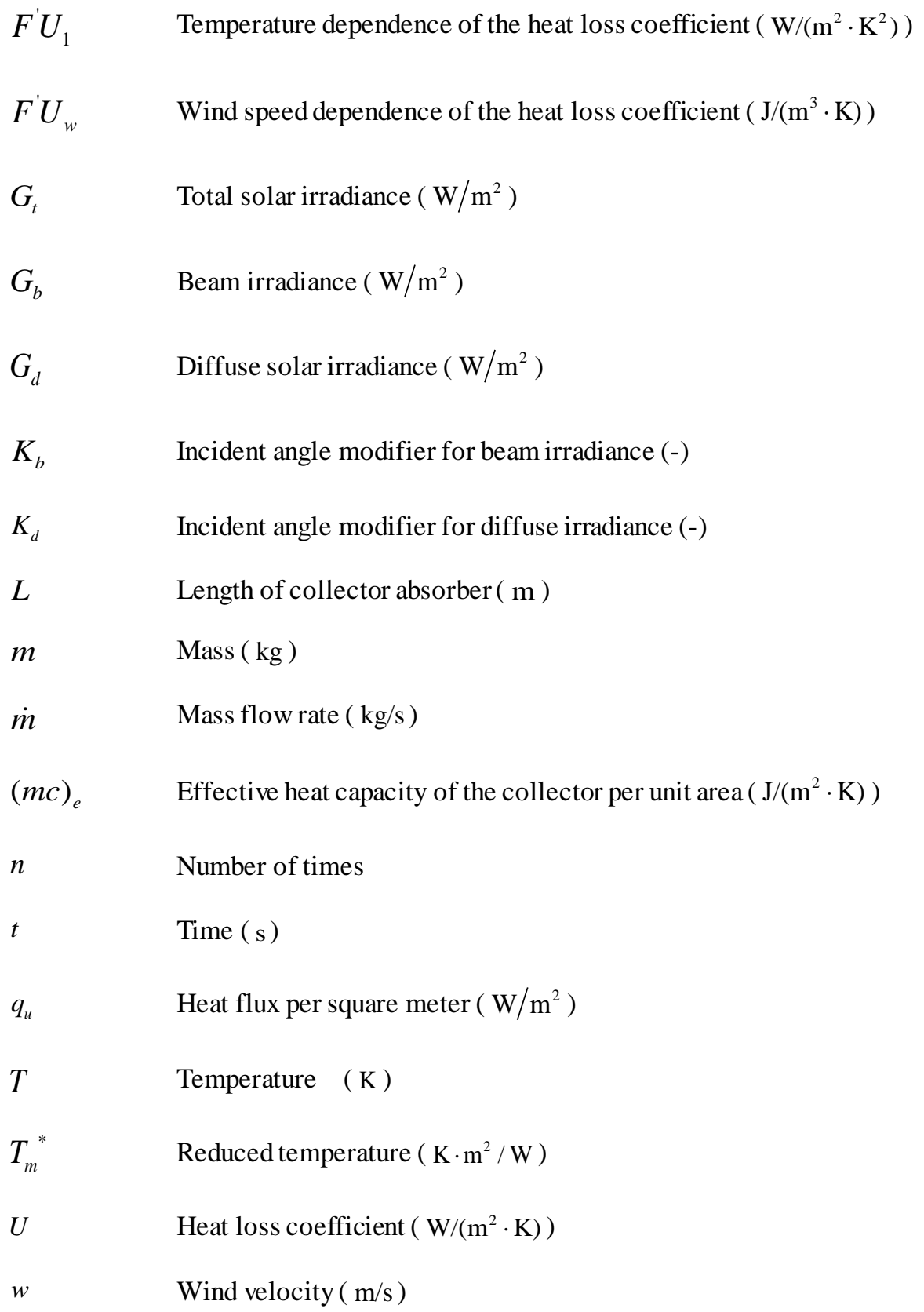

\section{Greek symbols}

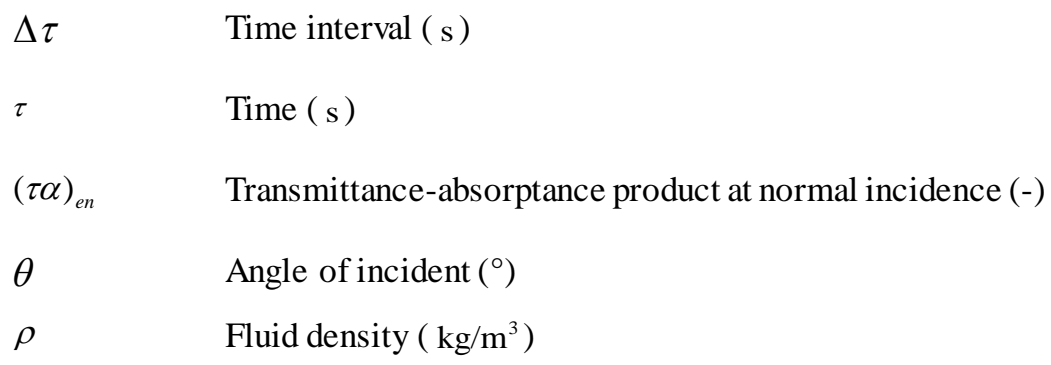

\section{Subscripts}

$\begin{array}{ll}\text { a } & \text { Ambient } \\ \text { c } & \text { Collector }\end{array}$




$\begin{array}{ll}\text { f } & \text { Fluid } \\ \text { fin } & \text { Collector absorber fin } \\ \text { fo } & \text { Fluid outlet } \\ \text { fi } & \text { Fluid inlet } \\ \text { w } & \text { Wind } \\ 0 & \text { Beginning }\end{array}$

\section{Introduction}

\subsection{Background}

The solar collector testing technology is mainly applied in the area of solar collector evaluation and thermal performance prediction. The definition and identification of solar collector parameters are the main tasks of solar collector testing. The collector parameters can have a variety forms by different test methods. The prevalent test method is the steady state test method which is adopted by most test standards around the world such as ISO 9806 [4], EN 12975-2 [5] and ASHRAE 93 [6]. The steady state test method is featured by its simple mathematical model and convenient data processing method. But the strict test conditions and high-precision data acquisition requirements limit its wide application in connection with outdoor testing. For example, in some regions, especially the north of Europe, it may take several months to acquire enough test data for one test. What's more, the cost of construction and maintenance of the high-precision data acquisition device and control instruments will be obviously high.

To overcome the drawbacks of the steady state test method mentioned above, different kinds of dynamic and quasi-dynamic test methods have been invented since 1980s [7]. Generally, the dynamic test method can be characterized by its relatively complicated mathematical model and data processing techniques but relatively loose test conditions, short test period and extensive adaptability. The QuasiDynamic Test (QDT) method [2] is the only dynamic test method adopted by the standard till now as an alternative method in EN 12975 [5] and ISO 9806 [4]. It is the representative of one node method which considers the solar collector and the fluid as a whole. The collector thermal capacity is lumped together and referenced by the mean fluid temperature. The transfer function method [8-11] and the improved transfer function (ITF) method [12] are typical multi-node test methods. The solar collector is divided into a solid part and a fluid part. Each part has its own thermal capacity which is referenced 
by each part's mean temperature. Other dynamic test methods are known as its unique mathematical model or data processing techniques such as response function method [13-16], the filter method [17], the Laplace transformation method [1], the thermal resistance method [18], the power correction method [19], etc.

\subsection{The Quasi-Dynamic Test (QDT) method}

The QDT method [20-22] was first developed by Bengt Perers in 1990 and adopted by the European standard EN 12975 [5] in 2000 and by the international standard ISO 9806 [4] in 2013. The QDT mathematical model is well known as Eq. (1). The left hand side of Eq. (1) is solar collector's effective power gain. While at the right hand side, the irradiance is divided into the beam and the diffuse term each with its incident angle modifier and the rest are the detailed heat losses terms. The accuracy of the QDT method has been validated by different independent research, see [7].

$$
\begin{aligned}
q u= & \dot{m} c_{f}\left(T_{f o}-T_{f i}\right) / A_{p}=F^{\prime}(\tau \alpha)_{e n} K_{b} G_{b}+F^{\prime}(\tau \alpha)_{e n} K_{d} G_{d}-F^{\prime} U_{L}\left(T_{f}-T_{a}\right) \\
& -F^{\prime} U_{1}\left(T_{f}-T_{a}\right)^{2}-F^{\prime} U_{w} w\left(T_{f}-T_{a}\right)-(m c)_{e} \frac{d T_{f}}{d t}
\end{aligned}
$$

Compared with the steady state test method, most of the test conditions are loosened in the QDT method. But the allowed deviation of the inlet temperature is still strictly restricted within $\pm 1 \mathrm{~K}$ during one test sequence and the flowrate should also be constant. The test duration is usually the same with the steady state test method and it was reported that the thermal capacity of solar collector may not always accurately be identified since the collector reacts under constant inlet temperature condition which could not supply enough collector dynamic response information [23].

\subsection{The New Dynamic Method(NDM)}

Amer and Nayak $[1,24]$ developed a new dynamic method (NDM) which is characterized by using the Laplace transformation method for the mathematical model development.

The NDM method is summarized as follows [1]. Consider an element of length $\Delta \mathrm{x}$ along the flow direction of the collector. Its width $w$ equals to the length between the axes of two adjacent riser tubes. The energy balance equation for the element at any time can be expressed as

$$
\dot{m} c_{f}\left[T_{f}(x+\Delta x, \tau)-T_{f}(x, \tau)\right]=F^{\prime}(\tau \alpha)_{e n} G_{t}(\tau) w \Delta x-F^{\prime} U_{L}\left[T_{f}(x, \tau)-T_{a}(\tau)\right] w \Delta x-(\mathrm{m} c)_{\Delta x} \frac{d T_{f}(x, \tau)}{d \tau}
$$

The effective thermal capacitance of the collector is considered to be uniformly distributed over the area of the collector, then 


$$
\frac{(\mathrm{m} c)_{\Delta x}}{w \Delta x}=\frac{(\mathrm{m} c)_{f i n}}{w L}=\frac{(\mathrm{m} c)_{e}}{A_{p}}
$$

Take limit of Eq. (2) can derive

$$
\frac{\partial T_{f}(x, \tau)}{\partial x}+\frac{F^{\prime} U_{L} A_{p}}{\dot{m} c_{f} L} T_{f}(x, \tau)=\frac{F^{\prime}(\tau \alpha)_{e n} A_{p}}{\dot{m} c_{f} L} G_{t}(\tau)+\frac{F^{\prime} U_{L} A_{p}}{\dot{m} c_{f} L} T_{a}(\tau)-\frac{(\mathrm{m} c)_{e}}{\dot{m} c_{f} L} \frac{\partial T_{f}(x, \tau)}{\partial \tau}
$$

The initial and boundary conditions are

$$
\begin{gathered}
T_{f}(x, 0)=T_{0} \\
T_{f}(0, t)=T_{f i}(t)
\end{gathered}
$$

Eq. (4) is solved by using the Laplace transformation technique which gives the final expression of the fluid mean temperature

$$
\begin{aligned}
T_{f}(x, \tau) & =\int_{0}^{\tau}\left[\frac{F^{\prime}(\tau \alpha)_{e n}}{(m c)_{e}} G_{t}(\tau-t)+\frac{F^{\prime} U_{L}}{(m c)_{e}} T_{a}(\tau-t)\right] \exp \left(\frac{F^{\prime} U_{L}}{(m c)_{e}} t\right) d t \\
& +T_{0} \exp \left(-\frac{F^{\prime} U_{L}}{(m c)_{e}} \tau\right)\left[1-u\left(\tau-\frac{\tau_{d} x}{L}\right)\right]+\exp \left(-\frac{\tau_{d} x}{\tau_{L} L}\right)\left[T_{f i}\left(\tau-\frac{\tau_{d} x}{L}\right) u\left(\tau-\frac{\tau_{d} x}{L}\right)\right] \\
& -\int_{0}^{\tau}\left[\frac{F^{\prime}(\tau \alpha)_{e n}}{(m c)_{e}} G_{t}(\tau-t)+\frac{F^{\prime} U_{L}}{(m c)_{e}} T_{a}(\tau-t)\right] \exp \left(\frac{F^{\prime} U_{L}}{(m c)_{e}} t\right) u\left(t-\frac{\tau_{d} X}{L}\right) d t
\end{aligned}
$$

Where

$$
\begin{gathered}
\tau_{d}=\frac{(\mathrm{m} c)_{e}}{\dot{m} c_{p}} \\
\tau_{L}=\frac{(\mathrm{m} c)_{e}}{F^{\prime} U_{L}}
\end{gathered}
$$

and $u\left(t-\frac{\tau_{d} X}{L}\right)$ is the unit step function.

As for a transient process from time zero to $\tau_{\mathrm{d}}$ and $\mathrm{x}$ equals to L, Eq. (7) can be simplified to express the outlet temperature at the end of transient period and can be rewritten as

$$
T_{f o}(\tau)=\int_{0}^{\tau_{d}}\left[\frac{F^{\prime}(\tau \alpha)_{e n}}{(m c)_{e}} G_{t}(\tau-t)+\frac{F^{\prime} U_{L}}{(m c)_{e}} T_{a}(\tau-t)\right] \exp \left(\frac{F^{\prime} U_{L}}{(m c)_{e}} t\right) d t+T_{0} \exp \left(\frac{F^{\prime} U_{L}}{(m c)_{e}} \tau\right)
$$

The right hand side of Eq. (10) consists of two terms. The first term represents the environmental conditions which can be interpreted as the input influence to the collector. The other term means the initial effect to the outlet temperature. The exponential function in both terms means the weighting factor of the effect contributing to the dynamic changes of temperature of each time step during transient operations. 
The integral equation can be discretized into Eq. (11) after the response time $\tau_{\mathrm{d}}$ is divided into $\mathrm{N}$ equal time segments. The environmental inputs at each of $\Delta \tau$ time step contribute to the final outlet temperature. $\tau_{\mathrm{d}}$ is chosen as the response of the collector to any transient input would reach $95 \%$ of the final steady state value.

$T_{f o}\left(\tau_{d}\right)=T_{0} \exp \left(\frac{F^{\prime} U_{L}}{(m c)_{e}} \tau_{d}\right)+\sum_{k=0}^{n-1}\left[\frac{F^{\prime}(\tau \alpha)_{e n}}{(m c)_{e}} G_{t}\left(\tau_{d}-k \Delta \tau\right)+\frac{F^{\prime} U_{L}}{(m c)_{e}} T_{a}\left(\tau_{d}-k \Delta \tau\right)\right] \exp \left(\frac{F^{\prime} U_{L}}{(m c)_{e}} k \Delta t\right) \Delta t$

Eq. (11) is a non-linear equation containing three unknown parameters $F^{\prime}(\tau \alpha)_{e n}, F^{\prime} U_{L}$ and $(m c)_{e}$. A standard optimization routine from [25] was recommended to obtain the three collector parameters.

The experimental method is similar to the time constant test. The solar collector is shielded by an opaque or semi-transparent shield for some time and then exposed to the sun for some time. These shielding and un-shielding experiments are implemented during all test period and the experimental data are then collected during these repeated activities.

It is shown in the paper [1] that the NDM method can give accurate and stable results and has high precision which is comparable with steady state test method. But the paper is still missing information on the detailed process for deriving the mathematical model and has no introduction of the computational method for the non-linear equation and no specific description of how to select and process test data. In addition, the derivation process of the mathematical model of the NDM method is relatively complicated and only three collector parameters have no advantage compared to the steady state test method.

In this paper a new dynamic test method based on the QDT mathematical model and the Laplace transformation techniques is developed. The new Laplace method is simpler in mathematical model derivation than the NDM method but contains more meaningful collector parameters. Two experimental methods and data processing method are specified. TRNSYS [3] simulation and experiments verification are also carried out for the two experimental methods. The results comparison shows that the new Laplace transformation method can obtain accurate collector parameters under transient weather conditions in solar collector testing area.

\section{The new Laplace transformation method}

\subsection{Mathematical model}


Considering a transient response process of a solar collector, the basic dynamic energy conservation equation Eq. (12) can be used as the governing equation. It has the same mathematical structure as the QDT model of Eq. (1).

$$
q u=\dot{m} c_{f}\left(T_{f o}-T_{f i}\right) / A_{p}=F^{\prime}(\tau \alpha)_{e n} G_{t}-F^{\prime} U_{L}\left(T_{f}-T_{a}\right)-(m c)_{e} \frac{d T_{f}}{d t}
$$

All the variables in Eq. (12) are the function of time. For simplicity’s sake, set the equation parameters to simple symbols $-\dot{m} c_{f} / A_{P}=A, F^{\prime}(\tau \alpha)_{e n}=B, F^{\prime} U_{L}=C,(m c)_{e}=D$.

By rearranging Eq. (12), the simplified governing equation is

$$
D \frac{d T_{f}}{d t}=B G_{t}-C\left(T_{f}-T_{a}\right)-A\left(T_{f o}-T_{f i}\right)
$$

The Laplace transformation technique used for both sides of Eq. (13) gives Eq. (14).

$$
(D s+C) T_{f}(s)=B G_{t}(s)+C T_{a}(s)-A T_{f o}(s)+A T_{f i}(s)+D T_{f}(0)
$$

The mean fluid temperature $\mathrm{T}_{\mathrm{f}}(\mathrm{s})$ in the Laplace space can be expressed as

$$
\begin{aligned}
T_{f}(s) & =\frac{B G_{t}(s)+C T_{a}(s)-A T_{f o}(s)+A T_{f i}(s)+D T_{f}(0)}{D s+C} \\
& =\frac{1}{s+\frac{C}{D}}\left[\frac{B}{D} G_{t}(s)+\frac{C}{D} T_{a}(s)-\frac{A}{D} T_{f o}(s)+\frac{A}{D} T_{f i}(s)+T_{f}(0)\right]
\end{aligned}
$$

Then the inverse Laplace transformation technique was applied to Eq. (15) and the final analytical solution of the mean fluid temperature $\mathrm{T}_{\mathrm{f}}(\mathrm{t})$ in the time space can be obtained as the following equation.

$$
\begin{aligned}
T_{f}(\tau) & =\int_{0}^{\tau}\left\{\frac{F^{\prime}(\tau \alpha)_{e n}}{(m c)_{e}} G_{t}(\tau-t)+\frac{F^{\prime} U_{L}}{(m c)_{e}} T_{a}(\tau-t)-\frac{\dot{m} c_{f}}{(m c)_{e} A_{P}}\left[T_{f o}(\tau-t)-T_{f i}(\tau-t)\right]\right\} \exp \left(-\frac{F^{\prime} U_{L}}{(m c)_{e}} t\right) d t \\
& +T_{f}(0) \exp \left(-\frac{F^{\prime} U_{L}}{(m c)_{e}} \tau\right)
\end{aligned}
$$

Eq. (16) is an integral non-linear equation which has clear mathematical structure and physical meaning. It can be explained as the following way. For a period $(0-\tau)$, the mean fluid temperature of a solar collector at the end time $\mathrm{T}_{\mathrm{f}}(\tau)$ equals to the initial effect of the mean fluid temperature at the beginning time $T_{f}(0)$ and the summation influence of the environmental parameters $\left(G_{t}, T_{a}, T_{f o}, T_{f i}\right.$, $\dot{\mathrm{m}})$ during the period of $(0-\tau)$. Each term has its own exponential function as the weighting factor to determine how much it contributes to the final mean temperature.

Eq. (16) contains three undetermined collector parameters $F^{\prime}(\tau \alpha)_{e n}, F^{\prime} U_{L}$ and $(m c)_{e}$. But the Laplace and the reverse Laplace derivation method can be easily applied to the QDT model because Eq. 
(1) and Eq. (12) have the same mathematical structure. The QDT model contains more meaningful collector parameters than Eq. (12). By applying the Laplace and reverse Laplace transformation treatment for the QDT model, the L-QDT (Laplace QDT) mathematical model can be obtained as

$$
\begin{aligned}
T_{f}(\tau)= & \int_{0}^{\tau}\left\{\frac{F^{\prime}(\tau \alpha)_{e n}}{(m c)_{e}} G_{b}(\tau-t)-\frac{F^{\prime}(\tau \alpha)_{e n} \cdot b_{0}}{(m c)_{e}}\left(\frac{1}{\cos (\theta)}-1\right) G_{f}(\tau-t)+\frac{F^{\prime}(\tau \alpha)_{e n} K_{d}}{(m c)_{e}} G_{d}(\tau-t)+\frac{F^{\prime} U_{L}}{(m c)_{e}} T_{a}(\tau-t)\right. \\
& +T_{f}(0) \exp \left(-\frac{F^{\prime} U_{L}}{(m c)_{e} A_{p}} \tau\right)
\end{aligned}
$$

Where

$$
\begin{gathered}
T_{1}(t)=\left[\mathrm{T}_{f}(\mathrm{t})-\mathrm{T}_{a}(\mathrm{t})\right]^{2} \\
T_{2}(t)=\left[\mathrm{T}_{f}(\mathrm{t})-\mathrm{T}_{a}(\mathrm{t})\right] \cdot \mathrm{w}(\mathrm{t})
\end{gathered}
$$

In Eq. (17), the beam incident angle modifier $\mathrm{K}_{\mathrm{b}}$ is modeled as the $\mathrm{b}_{0}$ equation which is shown in Eq. (20). Another alternative is the so called angle by angle method developed by Perers [21]. Or it can be called the extended MLR method in [2] . The beam irradiance in the collector plane is sorted into different columns based on the average incident angle. For example $10^{\circ}$ is chosen as the interval between the columns. Using higher angular resolution can get higher accuracy. The multi linear regression [12] and the non-linear regression can both use this method to get a set of collector efficiencies angle by angle together with the other collector parameters. The efficiencies under different incident angles can be obtained without any pre-determined models.

$$
K_{b}(\theta)=1-b_{0}\left[\frac{1}{\cos (\theta)}-1\right]
$$

\subsection{Discretization of the integral equation}

The integral expression of Eq. (16) should be discrete in the practical use. The period of a dynamic response process of solar collector from 0 to $\tau_{\mathrm{d}}$ is considered. $\tau_{\mathrm{d}}$ can be divided into $\mathrm{n}$ time intervals. Each time interval is $\Delta \mathrm{t}$, therefore $\mathrm{n} \Delta \mathrm{t}=\tau_{\mathrm{d}}$.

The discrete format of Eq. (16) is

$$
T_{f}\left(\tau_{d}\right)=T_{f}(0) \exp \left(-\frac{F^{\prime} U_{L}}{(m c)_{e}} \tau_{d}\right)+\sum_{k=0}^{n-1} M\left(\tau_{d}-k \Delta t\right) \exp \left(-\frac{F^{\prime} U_{L}}{(m c)_{e}} k \Delta t\right) \Delta t
$$

Where

$$
M(\mathrm{t})=\frac{F^{\prime}(\tau \alpha)_{e n}}{(m c)_{e}} G_{t}(\mathrm{t})+\frac{F^{\prime} U_{L}}{(m c)_{e}} T_{a}(\mathrm{t})-\frac{\dot{m} c_{f}}{(m c)_{e} A_{p}}\left[T_{f o}(\mathrm{t})-T_{f i}(\mathrm{t})\right]
$$


The same discrete method can also be used in the mathematical model of the L-QDT method of Eq.

(17). The theory is the same while the only difference is that the L-QDT model contains more collector parameters.

A simple example will be enough to illustrate the essence of this Laplace method and the discrete mathematical model of Eq. (21). A typical dynamic response process of a solar collector can be seen in Fig. 1 which shows the collector mean fluid temperature $\mathrm{T}_{\mathrm{f}}$ decreases with time. The time interval of each point is $2 \mathrm{~s}$. For simplicity, 4 nodes are chosen to represent the whole dynamic process. The first node is labeled as $t=1$ indicating the beginning of the dynamic process while the last node is marked as $t=4$ representing the end. Therefore totally $3 \Delta t$ time intervals are identified. Then the discrete format of Eq. (21) can be expressed as Eq. (23).

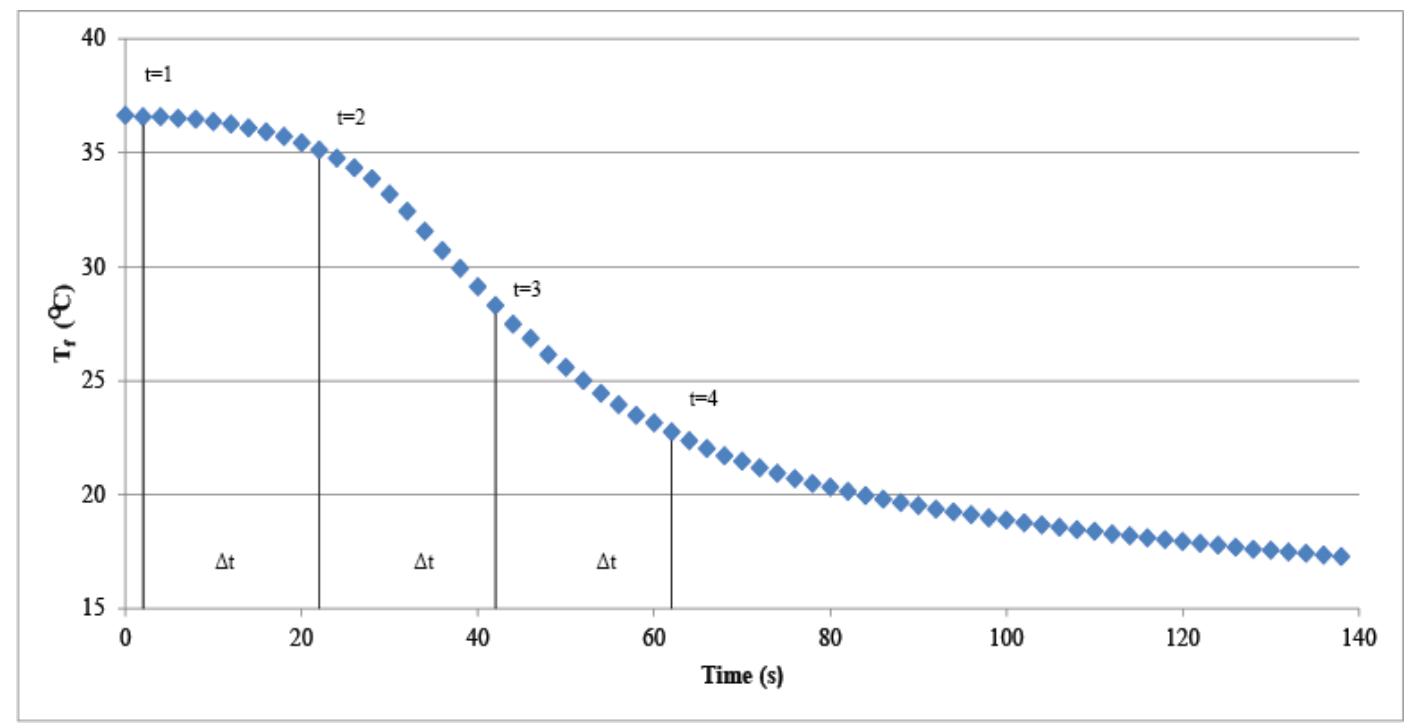

Fig. 1. Simplified 4 nodes example of a full response dynamic process of a solar collector

$$
\begin{aligned}
T_{f}(4)= & T_{f}(1) \exp \left(-\frac{F^{\prime} U_{L}}{(m c)_{e}} 3 \Delta t\right) \\
& +\left\{\frac{F^{\prime}(\tau \alpha)_{e n}}{(m c)_{e}} G_{t}(2)+\frac{F^{\prime} U_{L}}{(m c)_{e}} T_{a}(2)-\frac{\dot{m} c_{f}}{(m c)_{e} A_{p}}\left[T_{f o}(2)-T_{f i}(2)\right]\right\} \exp \left(-\frac{F^{\prime} U_{L}}{(m c)_{e}} 2 \Delta t\right) \Delta t \\
& +\left\{\frac{F^{\prime}(\tau \alpha)_{e n}}{(m c)_{e}} G_{t}(3)+\frac{F^{\prime} U_{L}}{(m c)_{e}} T_{a}(3)-\frac{\dot{m} c_{f}}{(m c)_{e} A_{p}}\left[T_{f o}(3)-T_{f i}(3)\right]\right\} \exp \left(-\frac{F^{\prime} U_{L}}{(m c)_{e}} 1 \Delta t\right) \Delta t \\
& +\left\{\frac{F^{\prime}(\tau \alpha)_{e n}}{(m c)_{e}} G_{t}(4)+\frac{F^{\prime} U_{L}}{(m c)_{e}} T_{a}(4)-\frac{\dot{m} c_{f}}{(m c)_{e} A_{p}}\left[T_{f o}(4)-T_{f i}(4)\right]\right\} \exp \left(-\frac{F^{\prime} U_{L}}{(m c)_{e}} 0 \Delta t\right) \Delta t
\end{aligned}
$$

The mathematical structure and physical meaning of Eq. (23) is also clear. For a dynamic response process, the collector final mean temperature $\mathrm{T}_{\mathrm{f}}(4)$ is determined by the initial mean temperature $\mathrm{T}_{\mathrm{f}}(1)$ and the historical environmental parameters. All the suitable dynamic response process will be selected from the raw data and used for identifying the collector parameters. 
Eq. (23) is a non-linear equation. The non-linear regression or the optimization method can be used for identifying the undetermined collector parameters. Standard programs of the two methods can be easily found in the math softwares such as Matlab [26] and R [27]. The difference between the non-linear regression method and the multi-linear regression method (MLR) is that the non-linear regression needs the initial values for the undetermined parameters. But as long as the governing equation and the test data are correct, the final results will be the same no matter what kind of non-linear regression method or initial values are used.

\section{Experimental test method}

Two experimental test methods are introduced in the following sections. One is an artificial intervention method which can be called the shielding method. This method creates dynamic response test data by shielding and un-shielding solar collectors. The other is the so called natural test method which does not need special manual intervention, just records and selects suitable test data from the routine solar collector test.

\subsection{The shielding and un-shielding experimental test method}

An opaque or semi-transparent cloth or board is used to shield the solar collector and pyranometer from sun light. It is recommended from the literature [1] that the irradiance measured by the shielded pyranometer should be less than $20 \%$ of total irradiance. Of course the best situation is that the cloth or board can block all the irradiance. The shield should be placed in parallel of the collector surface at a height of about $0.5 \mathrm{~m}$. The area of the shield is bigger than the collector area such that it extends beyond the collector edges by $0.5 \mathrm{~m}$ from all four sides.

The duration of shielding and un-shielding should be longer than two times of the collector time constant in order to achieve the full dynamic response data of solar collector. The purpose of shielding and un-shielding action is to create the collector dynamic response process artificially. Sufficient long shielding and un-shielding duration is the guarantee of a full dynamic reaction for solar collectors. According to the shielding theory above and the TRNSYS simulation results in section 4, this artificial intervention method can create useful dynamic response process as much as possible. Therefore, this shielding and un-shielding method can greatly save time in experiments.

Another important thing is the varying inlet temperature. It has been found that the inlet temperature should present considerable change through testing otherwise the heat loss factor as well as the thermal 
capacity of solar collector will not be properly estimated [23]. It is recommended that the inlet temperature varies from ambient temperature to the highest possible collector temperature if the test conditions allows.

Figs. 3-5 show the ideal shielding and un-shielding irradiance conditions which were created by TRNSYS.

\subsection{The natural experimental test method}

The natural experimental test method is free of the shielding and un-shielding actions. The only thing is to record all the variations of the collector parameters. The method based on the theory that the transient weather conditions can also create natural shielding and un-shielding effects during collector test. For example when the clouds pass over a solar collector, the shielding effect will be created while when the clouds leave away, the solar collector will react as the un-shielding condition. Then after the test, the suitable dynamic test data will be selected according to the following rules. Assume that the collector full response time is $\mathrm{T}$. T can be determined by the following test procedure - the collector is shielded from the sun in a steady state and then exposed to the sun until it reaches another steady state after removing the shielding. Or the collector is exposed to the sun in a steady state and then it is shielded until reaching another steady state. The time period between the two steady state conditions is the full response time $\mathrm{T}$ and the $63.2 \% \mathrm{~T}$ is defined as $\mathrm{T}_{\mathrm{C}}$. Therefore the test data in which the collector response time lies between $T_{C}$ and $T$ is chosen for identifying collector parameters. The method is verified in section 5 .

The two methods give different lengths of the mathematical model of Eq. (21). The shielding and un-shielding actions make fully reacted collector response processes therefore all the dynamic data substituted into Eq. (21) has full response time T while the natural experimental test data contains all kinds of collector response processes such as steady state data, fully reacted data, and of course most of them are partial dynamic response data. Only the data in which the response time lies from Tc to $\mathrm{T}$ will be selected.

A typical schematic diagram of the natural experimental test is shown in Fig. 2. The mean fluid temperature $T_{\mathrm{f}}$ varies with time under transient environmental conditions. From Fig. 2 it can be seen that the $\mathrm{T}_{\mathrm{f}}$ descending region caused by the total irradiance decrease corresponding to the shielding process and the $T_{f}$ rising region caused by the total irradiance increase corresponding to the un-shielding process. 


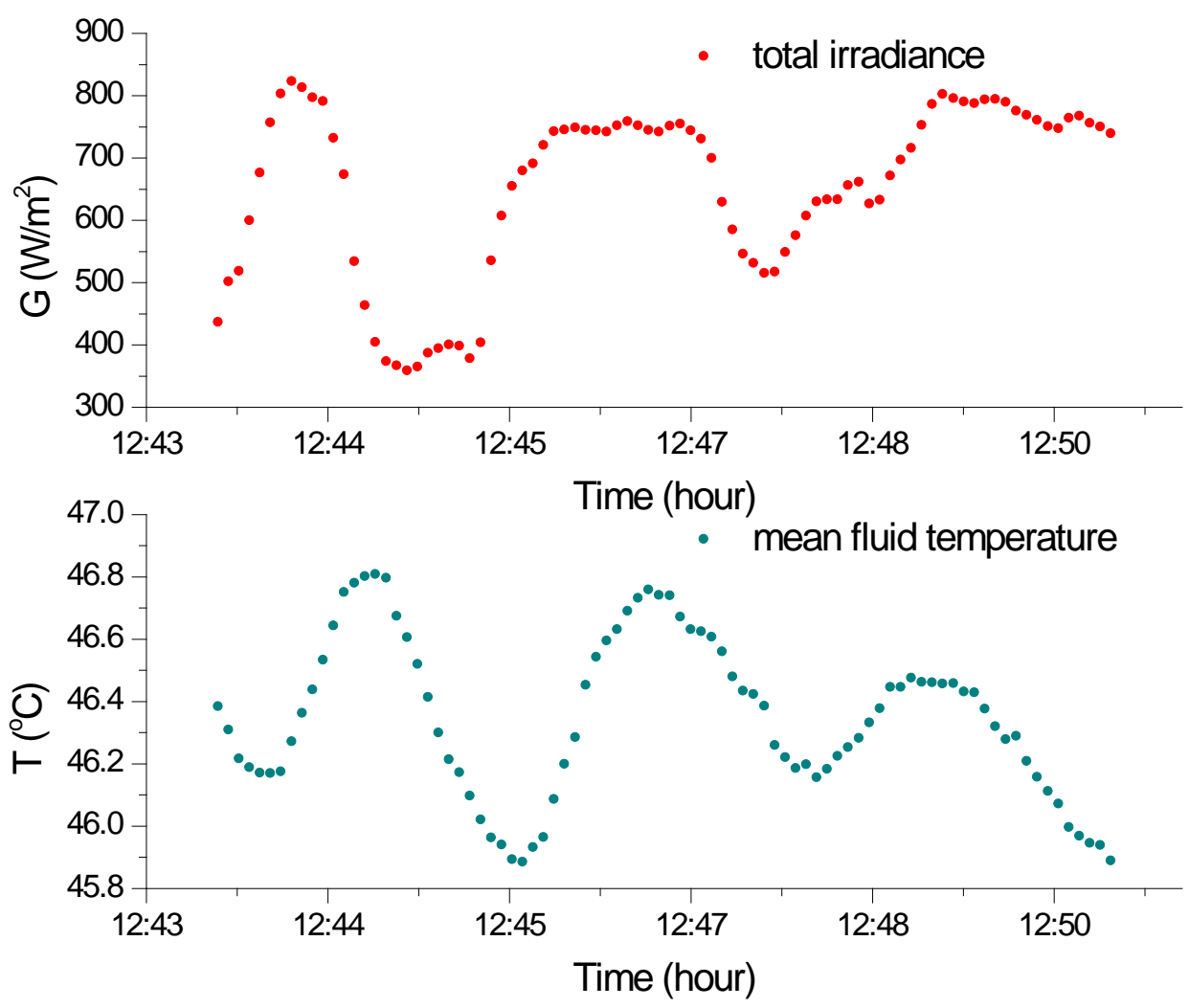

Fig. 2. A typical varying profile of mean fluid temperature under natural weather condition

\section{TRNSYS simulation for the shielding experimental method}

Theoretical calculations by using the shielding test method were carried out in TRNSYS simulation studio. The validated Type 832 solar collector model [28] was chosen to simulate the dynamic behavior of a flat plate solar collector under the DK-Kobenhavn-Taastrup weather data provided by TRNSYS 17. Three test days are chosen arbitrarily and the solar irradiance was processed by equation module to simulate the shielding and un-shielding effect. The weather conditions are plotted in Fig. 3 to Fig. 5. The setting values of the collector parameters are listed in Table 1 . The duration of shielding and un-shielding action is $7.5 \mathrm{~min}$ which is long enough for the dynamic response of the solar collector. Two data acquisition time of $5 \mathrm{~s}$ and $10 \mathrm{~s}$ with $72 \mathrm{~kg} / \mathrm{h}$ constant flow rate was set for the simulation test. The inlet temperature was designed to vary in sine profile between the ambient temperature and $90^{\circ} \mathrm{C}$. 
Table 1 The setting values of collector parameters in TRNSYS

\begin{tabular}{llll}
\hline Symbol & Collector parameter & Value & Unit \\
\hline $\mathrm{A}_{\mathrm{P}}$ & Collector aperture area & 1 & $\mathrm{~m}^{2}$ \\
$\mathrm{~F}^{\prime}(\tau \alpha)_{\mathrm{en}}$ & Zero loss efficiency & 0.7 & - \\
$\mathrm{b}_{0}$ & IAM parameter for beam radiation & 0.2 & - \\
$\mathrm{K}_{\mathrm{d}}$ & IAM for diffuse radiation & 0.9 & - \\
$\mathrm{F}^{\prime} \mathrm{U}_{\mathrm{L}}$ & Linear heat loss coefficient & 3 & $\mathrm{~W} / \mathrm{m}^{2} \mathrm{~K}$ \\
$\mathrm{~F}^{\prime} \mathrm{U}_{1}$ & Quadra heat loss coefficient & 0.01 & $\mathrm{~W} / \mathrm{m}^{2} \mathrm{~K}^{2}$ \\
$\mathrm{~F}^{\prime} \mathrm{U}_{\mathrm{w}}$ & wind loss coefficient & 0.1 & $\mathrm{~J} / \mathrm{m}^{3} \mathrm{~K}$ \\
$(\mathrm{mc})_{\mathrm{d}}$ & thermal capacity for the solid part & 5000 & $\mathrm{~J} / \mathrm{m}^{2} \mathrm{~K}$ \\
$(\mathrm{mc})_{\mathrm{f}}$ & thermal capacity for the fluid part & 1500 & $\mathrm{~J} / \mathrm{m}^{2} \mathrm{~K}$ \\
\hline
\end{tabular}
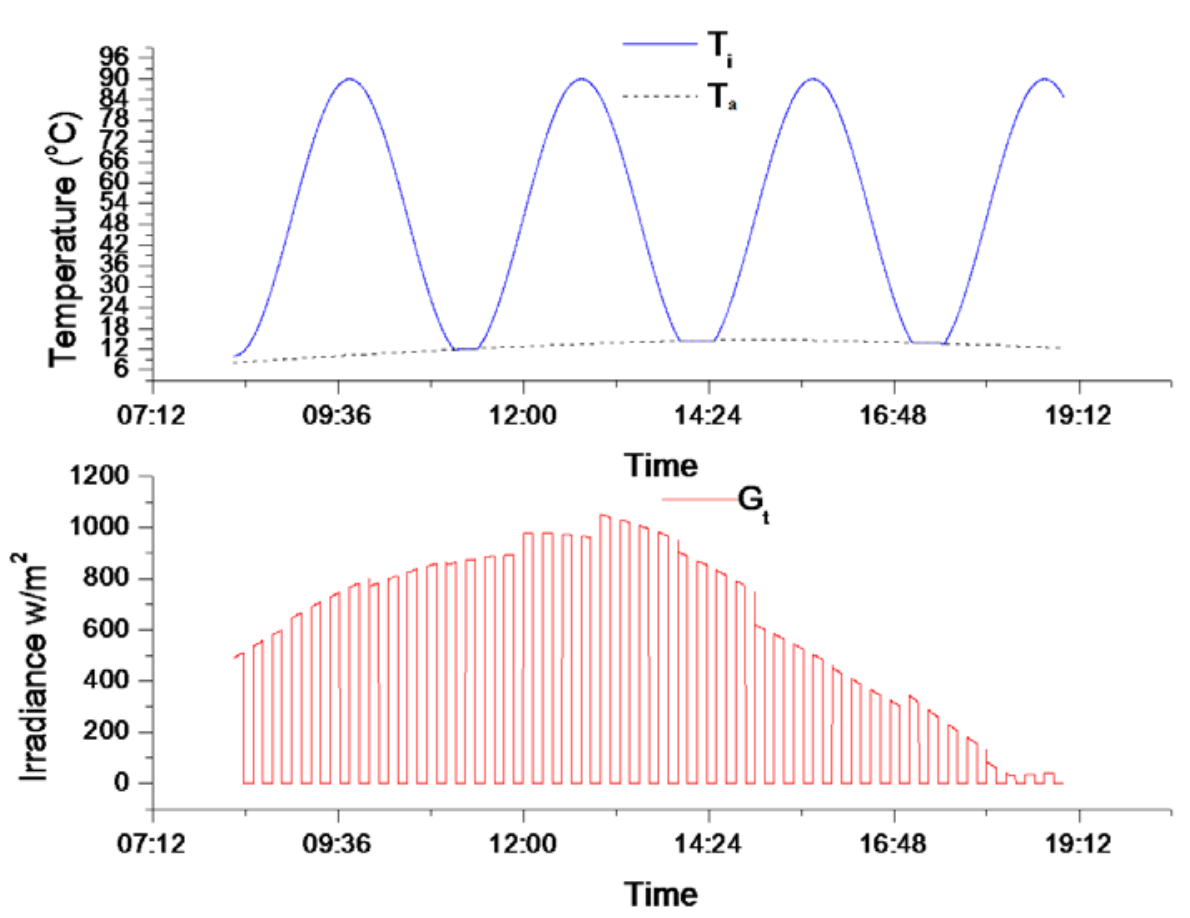

Fig. 3 The test condition of $1^{\text {st }}$ of May 

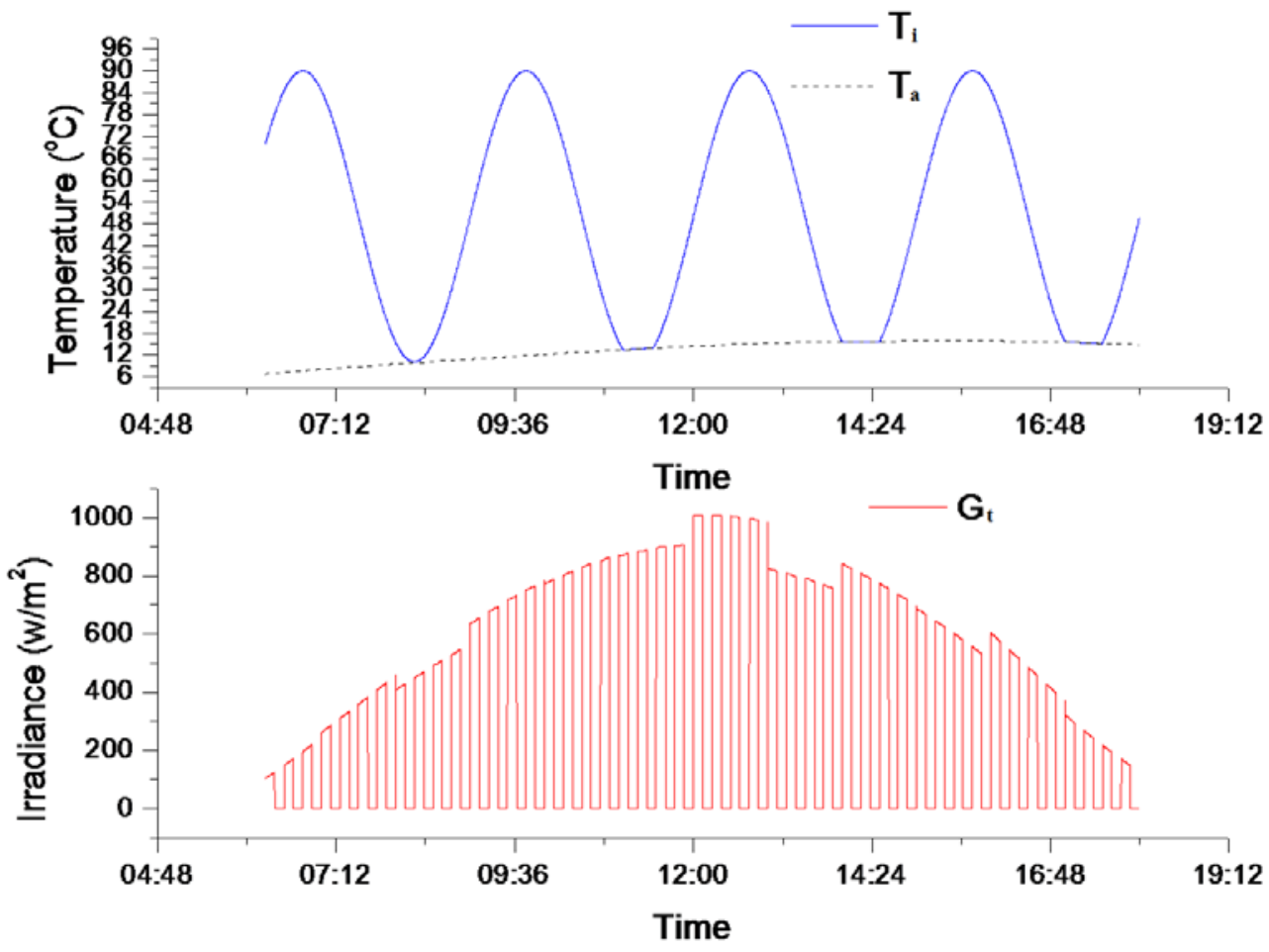

Fig. 4 The test condition of $2^{\text {nd }}$ of May
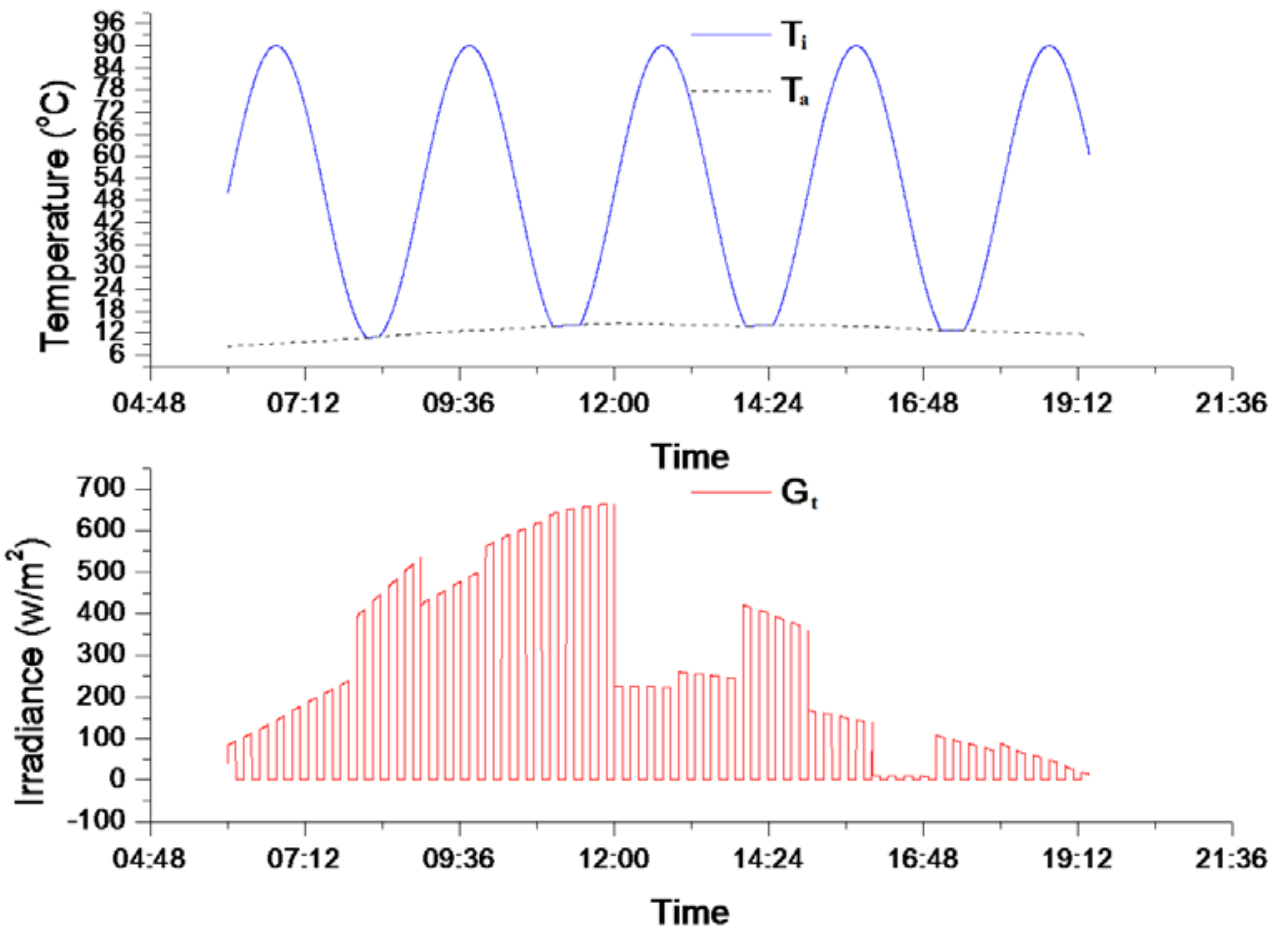

Fig. 5 The test condition of $3^{\text {rd }}$ of May 
Table 2 Comparison of collector parameters under different test conditions

\begin{tabular}{cccc}
\hline & & \multicolumn{2}{c}{ Data acquisition time interval } \\
Parameters & Setting value & $5 \mathrm{~s}$ & $10 \mathrm{~s}$ \\
\hline $\mathrm{F}^{\prime}(\tau \alpha)_{\mathrm{en}}$ & 0.7 & $0.66(5.7 \%)$ & $0.67(4.3 \%)$ \\
$\mathrm{b}_{0}$ & 0.2 & $0.20(0 \%)$ & $0.25(25 \%)$ \\
$\mathrm{K}_{\mathrm{d}}$ & 0.9 & $0.90(0 \%)$ & $0.92(2.2 \%)$ \\
$\mathrm{F}^{\prime} \mathrm{U}_{\mathrm{L}}$ & 3 & $2.80(6.7 \%)$ & $2.90(3.3 \%)$ \\
$\mathrm{F}^{\prime} \mathrm{U}_{1}$ & 0.01 & $0.02(100 \%)$ & $0.013(30 \%)$ \\
$\mathrm{F}^{\prime} \mathrm{U}_{\mathrm{w}}$ & 0.1 & $0.08(20 \%)$ & $0.09(10 \%)$ \\
$(\mathrm{mc})_{\mathrm{e}}$ & 6500 & $6740(3.7 \%)$ & $6701(3.1 \%)$
\end{tabular}

The collector parameters are identified by using the simulated test data and compared with the setting values which are shown in Table 2. The relative error of each collector parameter is illustrated in the bracket which is defined as $\left|\mathrm{P}_{\text {calculated }}-\mathrm{P}_{\text {setting }}\right| / \mathrm{P}_{\text {setting. }}$ It can be seen from Table 2 that all the collector parameters are successfully obtained and the results are close to the setting values except the quadratic heat loss coefficient $F^{\prime} U_{1}$. The relative error of the zero loss coefficient $F^{\prime}(\tau \alpha)_{e n}$, the heat loss coefficient $\mathrm{F}^{\prime} \mathrm{U}_{\mathrm{L}}$ and the collector thermal capacity $(\mathrm{mc})_{\mathrm{e}}$ are all under $7 \%$. The largest relative error comes from the quadratic heat loss coefficient $\mathrm{F}^{\prime} \mathrm{U}_{1}$. But the value of itself is very small and won't significantly affect the efficiency and energy output. Therefore the regression process can be considered successful.

\section{Experimental verification for the natural test method}

\subsection{Test platform and solar collector}

A flat plate solar collector was tested at the Technical University of Denmark on 18 June and 02-04 July 2014. The solar collector is designed for medium and large solar heating system with the gross area of $13.53 \mathrm{~m}^{2}$ and the aperture area of $12.56 \mathrm{~m}^{2}$. There is a transparent ETFE (Ethylene tetrafluoroethylene) foil equipped between the absorber and the surface glass with the aim to reduce the convection heat loss. Water was used as the working fluid.

The solar collector photograph and schematic diagram of the test rig are shown in Fig. 6 and Fig. 7 
respectively. Data of the test rig facilities are listed in Table 3. The slope of the test solar collector is $45^{\circ}$. The collector fluid is pumped through the solar collector with the fluid flow rate of $25 \mathrm{l} / \mathrm{min}$ during the whole test period. The fluid inlet temperature was controlled by the electrical heating and water cooling devices to make sure that it can vary during test. There were no requirements for weather conditions. All the data including the total irradiance $\left(G_{t}\right)$, the diffuse irradiance $\left(G_{d}\right)$, the ambient temperature $\left(T_{a}\right)$, the fluid inlet and outlet temperature $\left(T_{f i}\right.$ and $T_{\text {fo }}$ ) and the fluid flow rate (m) were recorded by the data logger. The time interval of data acquisition is $10 \mathrm{~s}$.

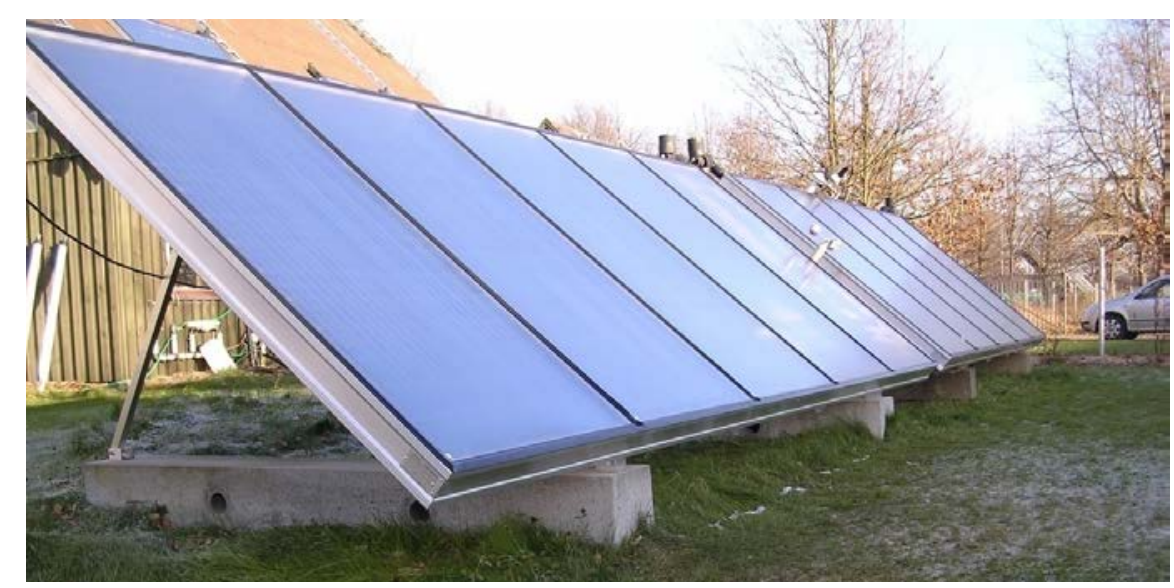

Fig. 6 Photograph of solar collector

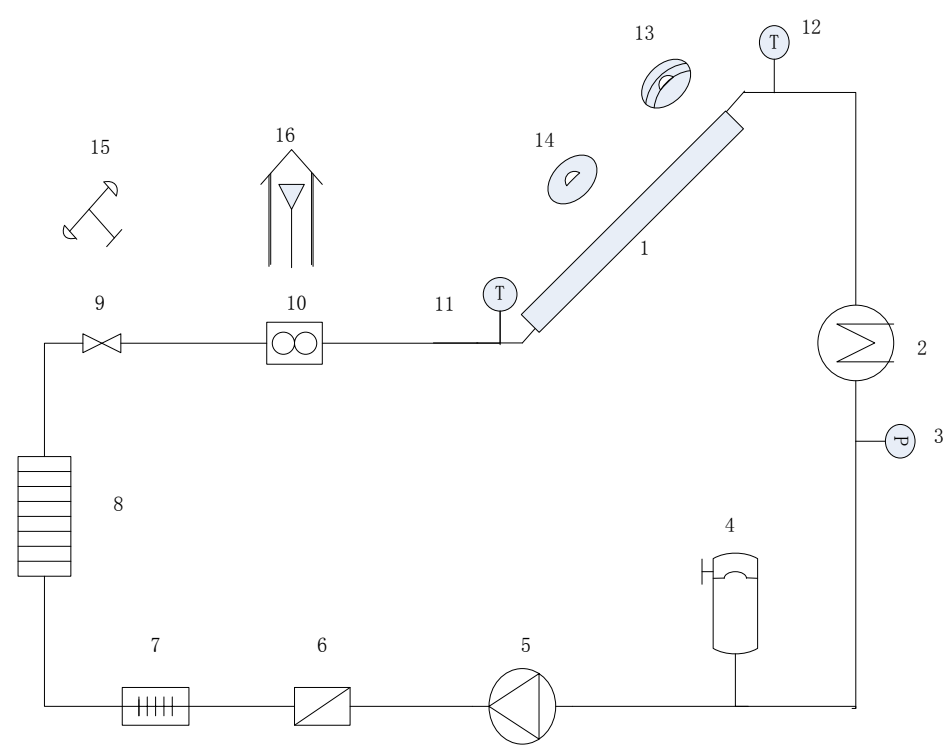

Fig. 7 Test rig schematic 


\begin{tabular}{clll}
\hline No. & Facility & No. & Facility \\
\hline 1 & Solar collector & 9 & Flow control valve \\
2 & Primary temperature regulator & 10 & Flow meter \\
3 & Pressure gauge & 11 & Inlet temperature sensor \\
4 & Expansion tank & 12 & Outlet temperature sensor \\
5 & Pump & 13 & Pyranometer with shadow band \\
6 & Filter & 14 & Pyranometer \\
7 & Electric heater & 15 & Anemometer \\
8 & Secondary temperature regulator & 16 & Ambient temperature sensor \\
\hline
\end{tabular}

\subsection{Test conditions}

The measurement data of the test period is shown below. The total and diffuse irradiance is illustrated in Fig. 8. The profile of the fluid inlet temperature and the ambient temperature can be seen in Fig. 9.

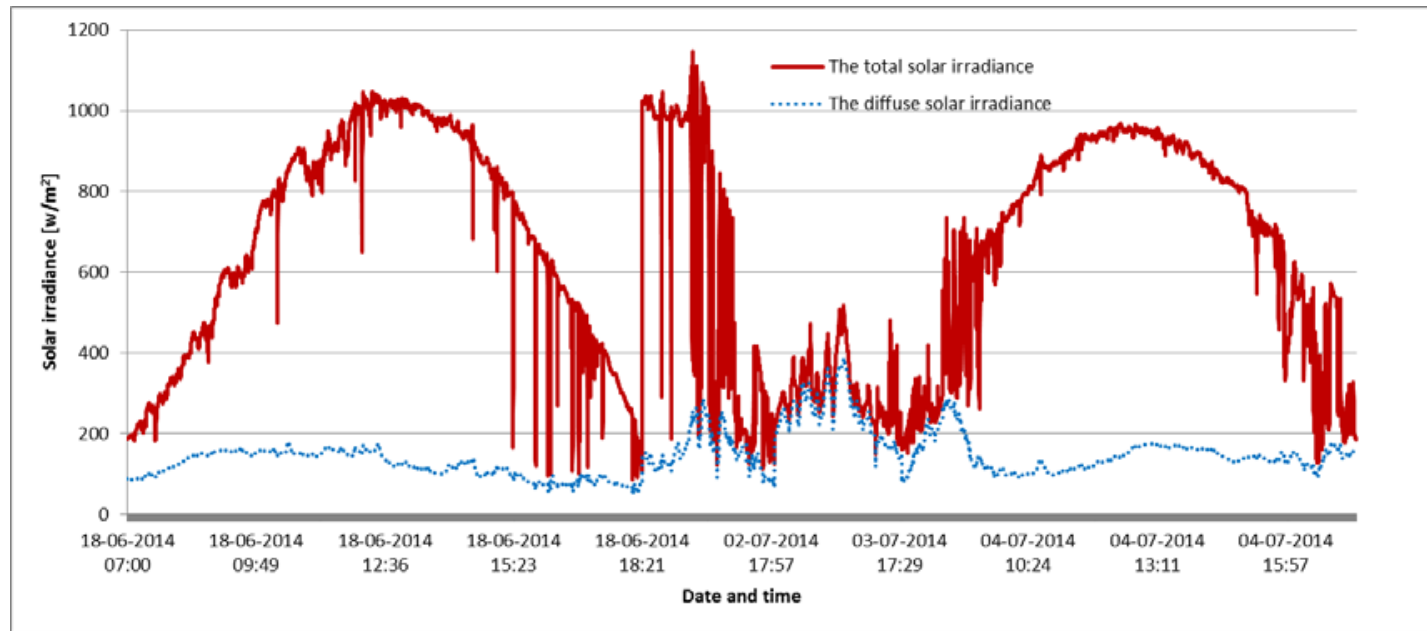

Fig. 8 The total and diffuse irradiance on collector surface during test period 


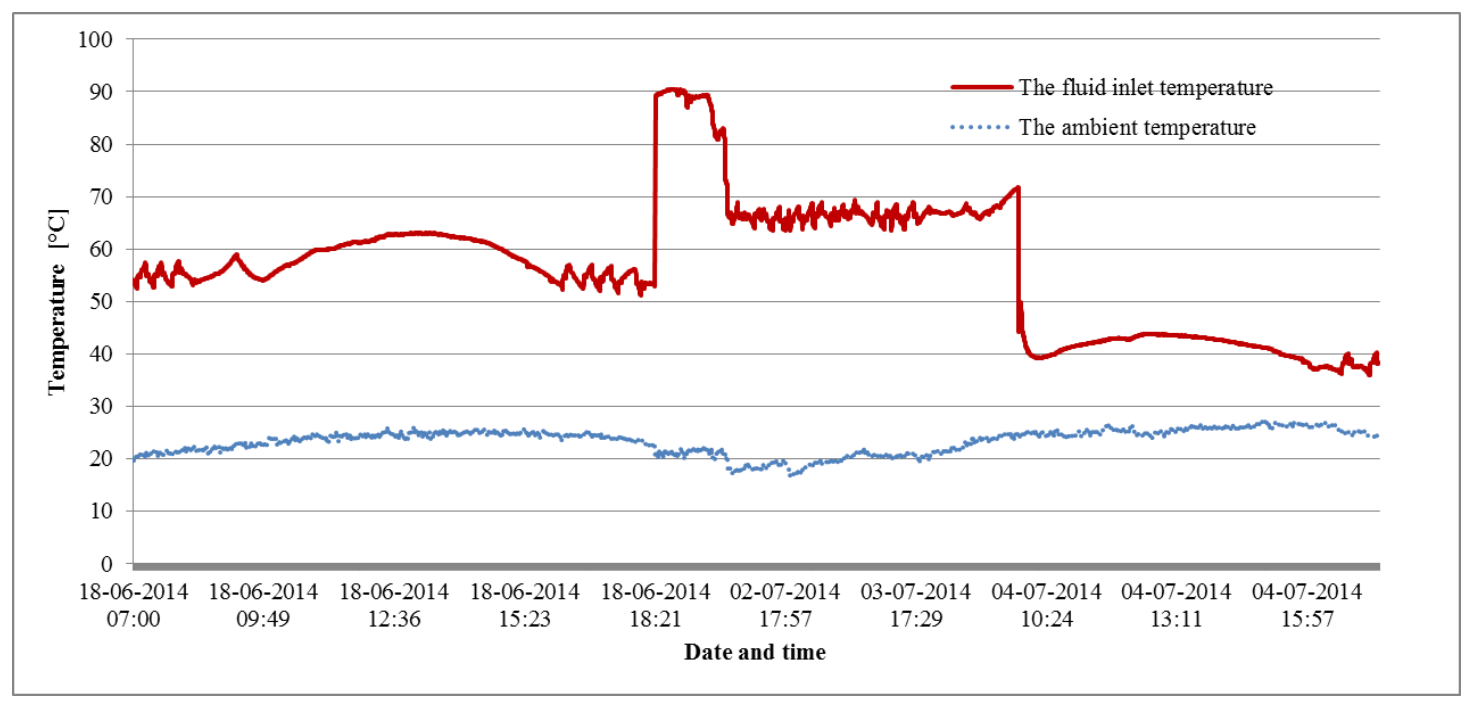

Fig. 9 The inlet temperature and ambient temperature during test period

It can be seen from Fig. 8 that the weather condition was unstable most of time. The drastic changing irradiance indicates that there were lots of crossing clouds during the test period. Actually, this cloud-crossing weather condition has similar effect as the collector shielding and un-shielding actions. Therefore the test data contains the collector's dynamic response information which can be used to calculate the collector's parameters.

\subsection{Resul ts and discussion}

The suitable L-QDT test data were selected from the raw data to identify the collector parameters. All the data processing, non-linear regression and statistics analysis were carried out at the R platform [27]. The steady state test data and the QDT test data are chosen from the test data of June and July 2014 based on the criteria of EN 12975-2 [5].

The full dynamic response time of the tested solar collector is $108 \mathrm{~s}$ and the time constant is $68 \mathrm{~s}$. The data acquisition time interval is $10 \mathrm{~s}$. Then the suitable dynamic data length of the L-QDT method can be determined between $70 \mathrm{~s}$ and $110 \mathrm{~s}$. Therefore the test data in which the dynamic response time is larger than $70 \mathrm{~s}$ and less than $110 \mathrm{~s}$ are chosen as useful data. In addition, the pretreatment for the raw data is also important for obtaining accurate results, such as the bad points removing and data filter technique [29]. It is noted that during the test period the shadow ring for measuring the diffuse irradiance was not well adjusted in the morning and the afternoon. Therefore the test data were filtered by the condition that the beam irradiance should be larger than $30 \mathrm{~W} / \mathrm{m}^{2}$ in order to remove the inaccurate diffuse irradiance.

The results of the model parameters with statistics are shown in Table 4 . The collector parameters 
calculated from Table 4 are shown in Table 5. The steady state test results, the QDT test results are also listed in the same table. The relative errors of the QDT and L-QDT method compared with the steady state results are present in the brackets.

It can be seen from Table 4 that the angle by angle method was used to describe the incident angle modifier (IAM) with the resolution of $15^{\circ}$. Fig. 10 shows the IAM comparison modelled by the L-QDT and the QDT angle by angle method and the $\mathrm{b}_{0}$ equation of the steady state method. The $\mathrm{b}_{0}$ value is obtained by modeling the efficiencies in Table 4 under different incident angles into the $b_{0}$ equation.

All the t values in Table 4 are larger than 2 indicates that the non-linear regression is valid and the estimated results are statistic reasonable.

From the results comparison of Table 5 it can be seen that the collector parameters identified by the L-QDT method are close to those obtained by the steady state method, especially the most important two collector parameters - the zero loss efficiency $F^{\prime}(\tau \alpha)_{\text {en }}$ and the heat loss coefficient $F^{\prime} U_{L}$. Both the $F^{\prime}(\tau \alpha)_{\text {en }}$ and the $F^{\prime} U_{L}$ have the relative errors less than $2 \%$. The QDT method also gives close results compared to the steady state test method. But the relative errors of $F^{\prime}(\tau \alpha)_{\text {en }}$ and $F^{\prime} U_{L}$ are a little bit larger than that of the L-QDT method. The linear efficiency curves obtained by the steady state method, the QDT method and the L-QDT method can be seen in Fig. 11 which shows the instantaneous efficiencies curves of the L-QDT method and the steady state method are very close.

The quadratic heat loss coefficient $\mathrm{F}^{\prime} \mathrm{U}_{1}$ has relative large difference by the two test methods compared with the steady state method. But it is due to the relatively "stable" inlet temperature which is lack of the information of the whole $\mathrm{T}_{\mathrm{m}}^{*}$ region, especially the high inlet temperature. The limited test data gives a higher value of the $\mathrm{F}^{\prime} \mathrm{U}_{1}$ which is reflected in the comparison of the quadratic efficiency curves in Fig. 12.

The $\mathrm{b}_{0}$ value of the two methods also has relative large difference which is mainly caused by the filter condition of $G_{b}>30 \mathrm{~W} / \mathrm{m}^{2}$. The filter condition is intended to eliminate the incorrect diffuse irradiance with the consequence of reducing the information of the high incident angle data which usually exist in the low beam irradiance condition. It is believed that the L-QDT and angle by angle method can give more accurate IAM results as long as sufficient test data provided.

In general the comparison shows that the natural experimental method can obtain reasonable collector parameters. 
Table 4 Model parameters and statistics based on the L-QDT method

\begin{tabular}{|c|c|c|c|c|}
\hline Coefficients & Estimate & Standard error & t value & $\mathrm{P}(>|\mathrm{t}|)$ \\
\hline$F^{\prime}(\tau \alpha)_{\left(0^{\circ}-15^{\circ}\right)}$ & $8.175 \times 10^{-1}$ & $1.753 \times 10^{-2}$ & 46.643 & $<2 \times 10^{-16}$ \\
\hline$F^{\prime}(\tau \alpha)_{\left(15^{\circ}-30^{\circ}\right)}$ & $7.946 \times 10^{-1}$ & $9.849 \times 10^{-3}$ & 80.675 & $<2 \times 10^{-16}$ \\
\hline$F^{\prime}(\tau \alpha)_{\left(30^{\circ}-45^{\circ}\right)}$ & $7.948 \times 10^{-1}$ & $9.741 \times 10^{-3}$ & 81.591 & $<2 \times 10^{-16}$ \\
\hline$F^{\prime}(\tau \alpha)_{\left(45^{\circ}-60^{\circ}\right)}$ & $7.354 \times 10^{-1}$ & $1.426 \times 10^{-2}$ & 51.560 & $<2 \times 10^{-16}$ \\
\hline$F^{\prime}(\tau \alpha)_{\left(60^{\circ}-75^{\circ}\right)}$ & $5.628 \times 10^{-1}$ & $2.797 \times 10^{-2}$ & 20.123 & $<2 \times 10^{-16}$ \\
\hline$F^{\prime}(\tau \alpha)_{\left(75^{\circ}-90^{\circ}\right)}$ & $3.368 \times 10^{-1}$ & $7.609 \times 10^{-2}$ & 4.427 & $1.28 \times 10^{-5}$ \\
\hline $\mathrm{F}^{\prime} \mathrm{U}_{\mathrm{L}}$ & 2.241 & $4.399 \times 10^{-1}$ & 5.095 & $5.74 \times 10^{-7}$ \\
\hline$F^{\prime}(\tau \alpha)_{\mathrm{en}} \cdot K_{d}$ & $8.099 \times 10^{-1}$ & $3.751 \times 10^{-2}$ & 21.591 & $<2 \times 10^{-16}$ \\
\hline $\mathrm{F}^{\prime} \mathrm{U}_{1}$ & $2.202 \times 10^{-2}$ & $5.983 \times 10^{-3}$ & 3.681 & $2.69 \times 10^{-3}$ \\
\hline$(\mathrm{mc})_{\mathrm{e}}$ & $5.405 \times 10^{3}$ & $2.086 \times 10^{2}$ & 25.913 & $<2 \times 10^{-16}$ \\
\hline
\end{tabular}

Table 5 Collector parameters comparison based on the steady state, the QDT and the L-QDT method

\begin{tabular}{ccccccc}
\hline Coefficients & $\mathrm{F}^{\prime}(\tau \alpha)_{\mathrm{en}}$ & $\mathrm{b}_{0}$ & $\mathrm{~K}_{\mathrm{d}}$ & $\mathrm{F}^{\prime} \mathrm{U}_{\mathrm{L}}$ & $\mathrm{F}_{1}$ & $(\mathrm{mc})_{\mathrm{e}}$ \\
\hline SST Estimate & 0.817 & 0.14 & - & 2.210 & 0.014 & - \\
QDT Estimate & $0.800(2.1 \%)$ & $0.18(28.6 \%)$ & 0.97 & $2.155(2.5 \%)$ & $0.022(57 \%)$ & 4092 \\
& & & & & & \\
L-QDT Estimate & $0.818(0.12 \%)$ & $0.19(35.7 \%)$ & 0.99 & $2.241(1.4 \%)$ & $0.022(57 \%)$ & 5405 \\
\hline
\end{tabular}




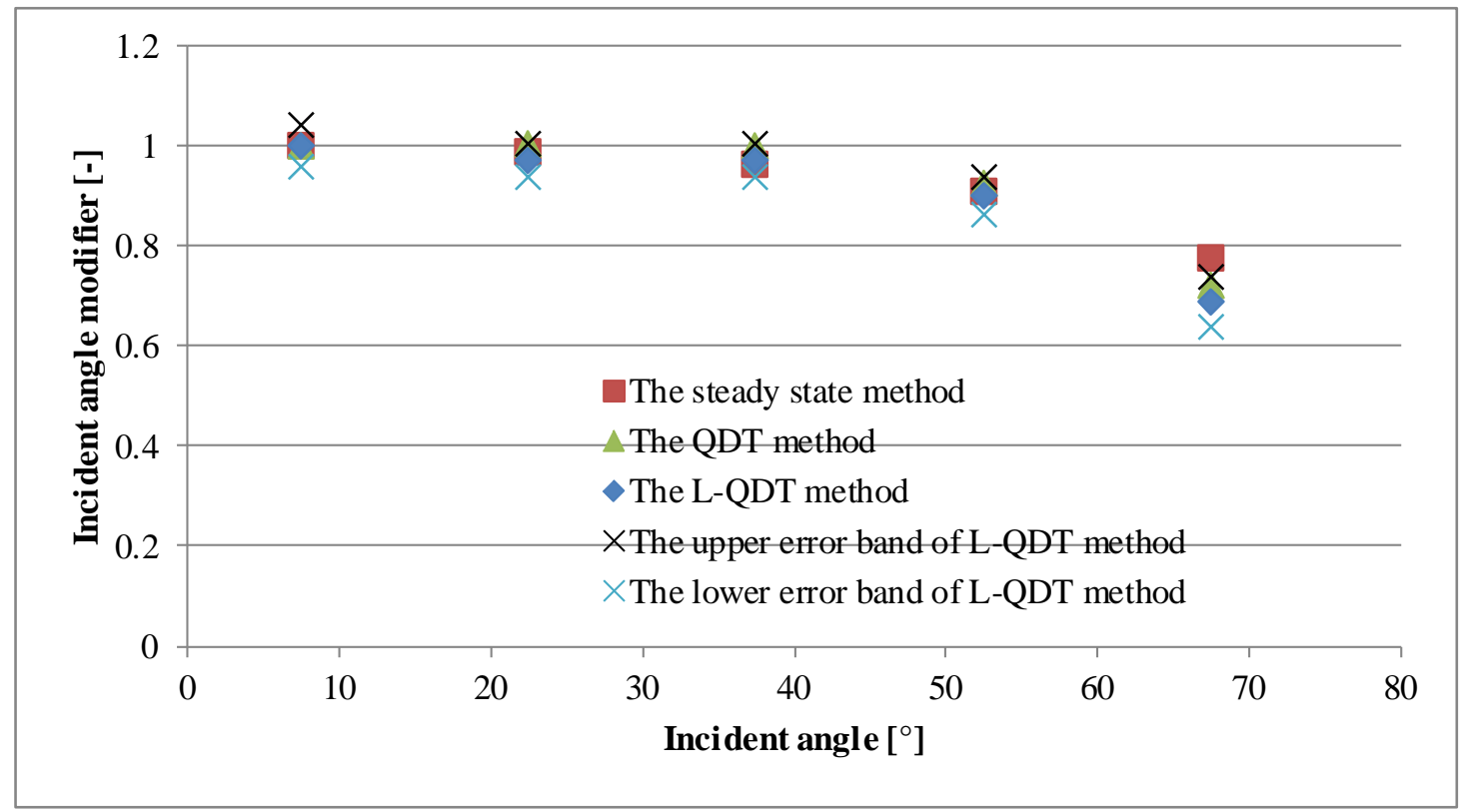

Fig. 10 The comparison of incident angle modifier by using the steady state, the QDT and the L-QDT method

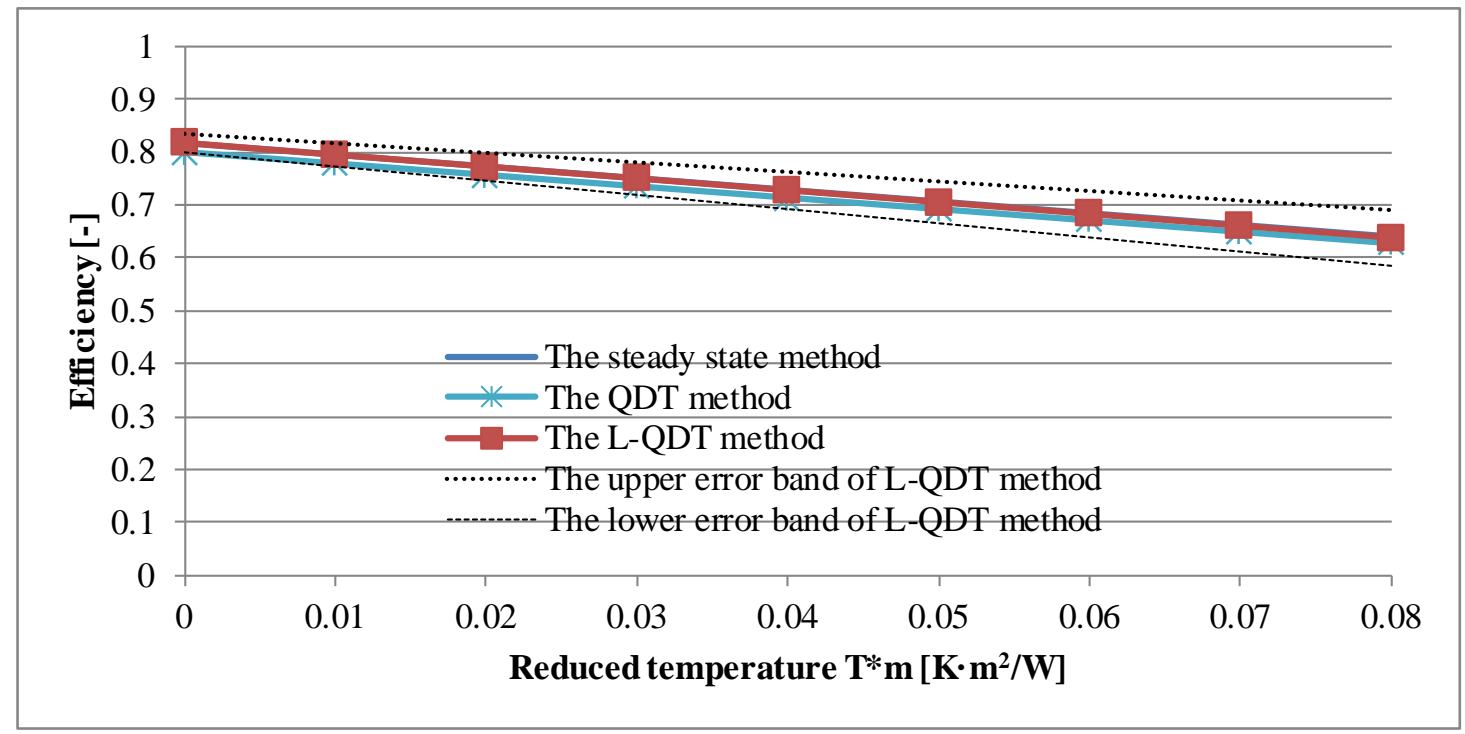

Fig. 11 The comparison of the linear efficiency curves by using the steady state, the QDT and the L-QDT method 


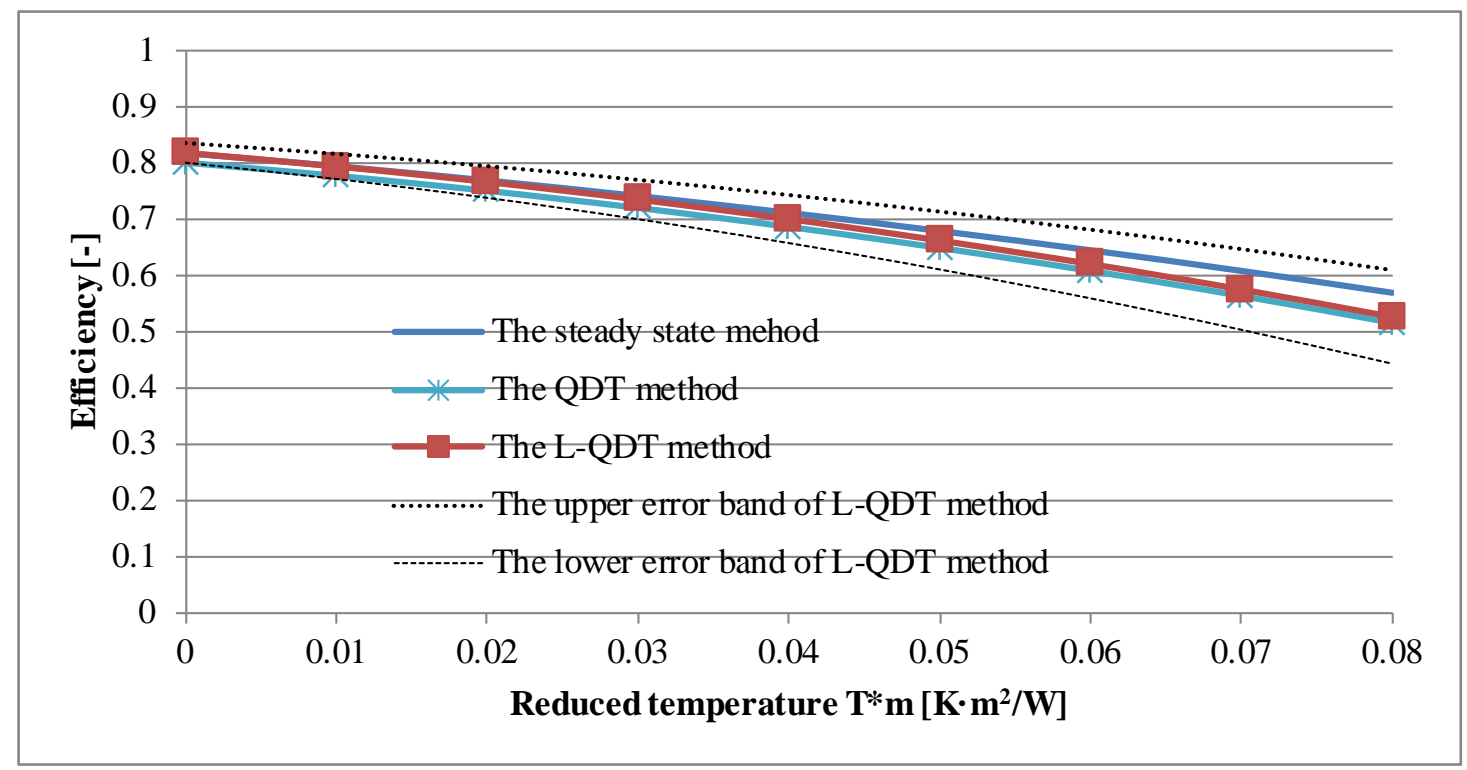

Fig. 12 The comparison of the quadratic efficiency curves by using the steady state, the QDT and the

L-QDT method

\section{Conclusion}

A brand new dynamic test method for solar collectors under transient weather conditions is developed. This new dynamic test method was characterized by using the Laplace transformation technique to solve the differential governing equation. This new Laplace transformation method can be easily expanded to combine with the QDT method. The L-QDT mathematical model is an analytical non-linear equation which describes the dynamic response process of solar collector and contains the same collector parameters as the QDT model. Two experimental methods are introduced. One is the shielding test method which needs to shield and un-shield the solar collector continuously during test period. The other is the so called natural experimental method which doesn't need manual intervention. The useful data need to be selected from the recorded test raw data. The natural test method is developed based on the theory that the unstable weather condition has the similar effect of shielding and un-shielding actions for solar collectors. The method of how to select and process data and the non-linear computation strategy are then specified.

TRNSYS simulation calculations are carried out to test the L-QDT method and the shielding experimental method. The test data was created by TRNSTS under different test conditions and used to identify the collector parameters. The results are then compared with the setting values defined by TRNSYS which show that the L-QDT mathematical model and the shielding experimental method can give accurate collector parameters under 5 or 10 s acquisition time interval. 
The natural experiments were carried out on 18 June and 02-04 July 2014 at the Technical University of Denmark. A flat plate solar collector equipped with the ETFE foil was tested. The collector parameters are identified by using the L-QDT model and the selected dynamic test data and then compared with the steady state and the QDT results. The results obtained from the three test methods are statistic analyzed and compared. The close results show that the L-QDT model and the natural experimental method can be used for collector dynamic testing.

The shielding and un-shielding method is a fast test method but needs manual intervention actions. The natural experimental method can be easily carried out and save workload but needs relatively longer time. The drastic changing weather is the best condition for the natural experimental method to select suitable dynamic test data.

Above all, it can be concluded that the new Laplace test method can achieve the function of evaluating solar collector by identifying accurate collector parameters under transient weather conditions. But for a complete test method, further studies are still needed on the investigation of the behavior of the method for the complete range of the acceptable testing conditions and for different collector types, in order to obtain safe conclusions regarding the repeatability, accuracy and robustness of the method.

\section{Reference}

[1] Amer, E. H., Nayak, J. K., and Sharma, G. K., 1999, "A new dynamic method for testing solar flat-plate collectors under variable weather," Energy Conversion and Management, 40(8), pp. 803-823.

[2] Fischer, S., Heidemann, W., Muller-Steinhagen, H., Perers, B., Bergquist, P., and Hellstrom, B., 2004, "Collector test method under quasi-dynamic conditions according to the European Standard EN 12975-2,"Solar Energy, 76(1-3), pp. 117-123.

[3]Klein, S., "TRANSYS, a transient system simulation program, Rep. 38-12," Solar Energy Laboratory, University of Wisconsin, MA, USA (Apr. 1988).

[4] ISO 9806, "Solar energy- Solar thermal collectors -Test methods"Geneva, Switzerland, 2013

[5] EN 12975-2, "Thermal solar systems and components-solar collectors- Part 2:Test methods.", 2006

[6] ASHRAE 93-2003, "Methods of testing to determine the thermal performance of solar collectors."

[7] Nayak, J. K., and Amer, E. H., 2000, "Experimental and theoretical evaluation of dynamic test procedures for solar flat-plate collectors," Solar Energy, 69(5), pp. 377-401.

[8] Kong, W., Wang, Z., Li, X., Li, X., and Xiao, N., 2012, "Theoretical analysis and experimental verification of a new dynamic test method for solar collectors,"Solar Energy, 86(1), pp. 398-406.

[9] Hou, H. J., 2004, "A transient test method for thermal performance of flat-plate solar collectors," Acta Energiae Solaris Sinica(3), pp. 310-314.

[10] Wang, B. W., 2008, "Solar Collector Thermal Performance Dynamic Test," Master' Thesis Master' Thesis, Master' Thesis. 
[11] Xu, L., 2009, "Research on Dynamic Test Method for Thermal Performance of Solar Collectors," Northeast University, Master' Thesis.

[12] Kong, W. Q., Wang, Z. F., Fan, J. H., Bacher, P., Perers, B., Chen, Z. Q., and Furbo, S., 2012, "An improved dynamic test method for solar collectors,"Solar Energy, 86(6), pp. 1838-1848.

[13] Rogers, B., 1981, "A method of collector testing under transient conditions," In Proceedings ISES Solar World Forum, Pergamon Press, New York.

[14] Emery, M., and Rogers, B., 1984, "On a solar collector thermal performance test method for use in variable conditions," Solar Energy, 33, pp. 117-123.

[15] Prapas, D. E., Norton, B., Milonidis, E., and Probert, S. D., 1988, "RESPONSE FUNCTION FOR SOLAR-ENERGY COLLECTORS," Solar Energy, 40(4), pp. 371-383.

[16] Prapas, D. E., Norton, B., and Probert, S. D., 1989, "TRANSIENT PERFORMANCE TESTING OF A PARABOLIC TROUGH CONCENTRATING SOLAR-ENERGY COLLECTOR," Proc. Inst. Mech. Eng. Part C-J. Eng. Mech. Eng. Sci., 203(1), pp. 21-29.

[17] Wang, X. A., Xu, Y. F., and Meng, X. Y., 1987, "A filter method for transient testing of collector performance,"Solar Energy, 38(2), pp. 125-134.

[18] Rodriguez-Hidalgo, M. C., Rodriguez-Aumente, P. A., Lecuona, A., Gutierrez-Urueta, G. L., and Ventas, R., 2011, "Flat plate thermal solar collector efficiency: Transient behavior under working conditions. Part I: Model description and experimental validation," Appl. Therm. Eng., 31(14-15), pp. 2394-2404.

[19] Horta, P., Carvalho, M. J., and Fischer, S., "Solar thermal collector yield: experimental validation of calculations based on steady-state and quasi-dynamic test methodologies," Proc. Ist Internaltional Congress on Heating, Cooling, and Buildings.

[20] Perers, B., 1993, "Dynamic Method for Solar Collector Array Testing and Evaluation with Standard Database and Simulation Programs," Solar Energy, 50(6), pp. 517-526.

[21] Perers, B., 1997, "An improved dynamic solar collector test method for determination of non-linear optical and thermal characteristics with multiple regression," Solar Energy, 59(4-6), pp. 163-178.

[22] Perers, B., Walletun, H., and Energy, S., "Dynamic Collector Models for 1 hr Time Step Derived From Measured Outdoor Data," Pergamon Press, p. 1221.

[23] Perers, B., Kovacs, P., and Pettersson, U., 2011, "Experiences and lessons learned from 30 years of dynamic collector testing, modelling and simulation," 30th ISES Biennial Solar World Congress 2011, SWC 2011, 6, pp. 4431-4438.

[24] Nayak, J., Amer, E., and Deshpande, S., 2000, "Comparison of three transient methods for testing solar flat-plate collectors,"Energy Conversion and Management, 41(7), pp. 677-700.

[25]Harwell Subroutine Library, 1985, Subroutine No. VA05AD. AERE-R-9185, 6th ed. Computer Science and Systems Division, Harwell Laboratory, Oxfordshire.

[26]Matlab, 2010,The MathWorks Inc., Natick, Massachusetts.

[27]R Development Core Team, 2011, R: "A language and environment for statistical computing. R Foundation for Statistical Computing, Vienna, Austria. ISBN 3-900051-07-0, URL http://www.R-project.org/."

[28] Haller, M., 2012, "TRNSYS Type 832 v5.00 "Dynamic Collector Model by Bengt Perers" Updated Input-Output Reference". 
[29] Kong, W., Wang, Z., Fan, J., Perers, B., Chen, Z., Furbo, S., and Andersen, E., 2012, "Investigation of Thermal Performance of Flat Plate and Evacuated Tubular Solar Collectors According to a New Dynamic Test Method," Energy Procedia, 30(0), pp. 152-161. 